\title{
Reflection on the Present Strategies of War on Doping
}

\author{
Jing Gao* \\ School of Physical Education, Changzhou University, Changzhou, China \\ E-mail: 284611656@QQ.COM
}

Keywords: War on Doping; War on Drugs; Damage Reducing; Alternative Strategy; Zero-tolerance

\begin{abstract}
From the practicalwar on drugs, it is well recognized and agreed to implement the policy to reduce damages of drugs in theoretical level as well as practical level. Since there are many similarities between the war on doping and the war on drugs, it means that the developing trend of these two types of war appears to merge. Following the damage reducing strategy adopted in the war on drugs, researchers may find some alternative methods towards the war on doping in sports in the future.
\end{abstract}

\section{Introduction}

Facilitated by the Olympic Games, the World Anti-Doping Agency (WADA) was established in 1999, which was responsible for the validating and adjusting the list of banned substances, identifying drug-testing laboratories and conducting anti-doping research, education and prevention. WADA's goal is to stand in a "zero tolerance" in height, and wipe out doping behavior. WADA the World Anti-Doping Code was promulgated in 2003, UNESCO's General Conference adopted the International Convention against doping in sport in 2005, thus making the World Anti-Doping Agency, the World Anti-Doping Code is mandatory. The anti-doping efforts are called dope wars.

Drugs become a major social problem, which caused widespread concern from the beginning of the 1950 . On June 30, 1961, the General Assembly adopted the single Convention on Narcotic Drugs of 1961. In 1971, the United States President Richard Nixon launched a "war on drugs", made a series of political, economic, legal and diplomatic measures for all-out war on drugs and cut the drug supply chain. Since then, the worldwide anti-drug movement has been in full swing, and countries all over the world presented in the "tough on crime" stance, a very harsh blow against drug-related crime and punishment, which are called the war on drugs.

\section{Making the damages-reducing, even non-criminal and legal measures and policies has been the trend in war on drugs}

Since Obama came to power from Jan, 2009, he has admitted in public that the "war on drugs" lasting for 40 years has failed, and claimed to give up using the word "war on drugs"[1]. The Uruguay President, Musica thought the "repression" of the war on drugs was determined a failed war. The Chairman of the Global Drug Policy Committee and Brazil President, Fernando Henrique Cardoso; member and the former Colombia President, Guweiliya and member and the former Mexico President, Cha Diyue all believe that following the present modes for anti-drug war is futile[2].

Global drug policy committee advocates for legal using drugs. The reason is that the cannabis is not only the most widely used drugs in the world, but also the power base for drug trafficking organizations. However, the academic studies have shown that the harmful effects to the human health of tobacco and alcohol were more than of marijuana. If Governments will decriminalize using marijuana, draw up public health policies, as well as address the issue of alcohol and tobacco to marijuana legal norms and controls, it will be a positive impact on dismantling the power structure of drug trafficking organizations. The Nobel Laurites in Economics, Milton 
Friedman and Gary Becker agreed to legalize drugs. They argued that legalization of drugs could make drug price cut, reducing costs of drug deals, reducing the financial burden on the addicts, and therefore addicts will reduce crime. What more, after the legalization of drugs, the spreading of AIDS due to a drug problem will disappear. Addicts no longer uses disposable syringes secretly; the cost of salaries issued to drug officers will transfer to helping drug addicts to giving up; Taxes heavily on the legal drugs trade, and the income help tackle Government budget issues; the Government can focus their energy on punishing the cases of selling drugs to the young people.

At present, some countries and regions have implemented the policies of harm reduction, non-criminal even legalized drugs. Netherlands is the first European country where it is legal to sell cannabis at certain extent, it also pursued a policy of legalizing soft drugs trade, and the Government openly set up "coffeshop" to sell drugs legally, the Government periodically supply hard drugs to addicts, and the office of magazine will give the reader cannabis seeds. In 2000, Germany adopted the Narcotics method amendment, and it was allowed to establish narcotics injection room publicly, and in united union Conference, Germany and Netherlands proposed a bill to legalize the drug globally. In 2001, Australia set up legally heroin injection center; In Swiss, distributing and planting marijuana has become serious of grey commercial regional, most of people advocated to make marijuana "legalized" [3]. In 2001, Portugal passed a law: individual drug usage and possession of drugs (including marijuana, cocaine, heroin and stimulants) are no longer regarded as a criminal offence. When the drug users were caught, hand in the fine and go. It is the first European countries' official non-crime for drugs [4]. In United States, Colorado, Washington states legislated to permit recreational industry of marijuana in 2012 [5]. Uruguay became the first country to legalize marijuana industry since 12.24.2013, which means the chain of cannabis production, distribution and marketing as a whole is legal in Uruguay [6].

\section{The Anti-doping War and Anti-drug War Have the same Trend}

The Similarity between War on doping and War on Drugs. Abuse of stimulants and drugs are harmful to human health, which is the important reason for anti-doping and anti-drug wars. In the aspect of body health, abuse of doping and drugs may lead to movement disorders, ordination obstacles, immunity declined, metabolism disorder, and function obstacles for liver 、 kidney organ, cardiovascular disease, malignant lesions or metamorphosis to sex reproductive system, various cancer, central nervous function declined, endocrine disorders, death, and so on. It also will affect human normal reproductive capacity, and affect the health of the next generation. Psychologically, the abuse of stimulants and drugs tend to produce hallucinations, delusions, thought disorder and psychopathic behavior, and finally loss of humanity and intellectuality, and do suicide.

War on drugs and war on doping is a "zero-tolerance" attitude, repression, monitoring, management, and penalties for all acts relating to illegal or irregular. Doctor-turned-Roger the beginning called for doping "zero tolerance" and called the national sports associations must accept the unity of IOC anti-doping standards, or they will be removed from the Olympic family. Zero tolerance also entered the Clinton Administration Justice Department 1999 -year 5 month "break the vicious cycle of drugs and crime," enforcement policy.

Doping and drug use are drug abuse and indistinguishable. International Olympic Committee publishes the list of prohibited drugs, including marijuana, heroin, cocaine and other drugs. Some substances also appears in the "Dope wars" on the list of banned substances because of the "war on drugs" influence, such as cannabis, and has caused controversy due to banned substances, and cannabis in Western society has become a popular recreational drug.

Both inputs and outputs are not in proportion. Take United States for example. United States Government funding for drug law enforcement up to 44.1 billion dollars a year, and seized drugs worth just a year to 150 million dollars, less than the Government's anti-drug $1 \%$ put on. Even more striking is that after the high-pressure fight against drug crime, violence and drug-related crime did not fall but rose. Currently in United 
States prisons for crimes, nearly one-third and drug-related crime, jail for drug-related crimes each year from 40,000 in 1980 has increased to the current 500,000. In 2010 year, United States Anti-Doping Committee (USADA) cost $15247296 \$ 8031$ samples were examined, indicating that the average found a case of illegal costs of up to 40 Million US dollars. Detected in only 38 cases, there are 285 cases of failure to provide required whereabouts information, and 61 cases missing pursuant to reasonable rules of the investigation.

The Present Difficulties of War on Doping. Although the World Anti-Doping Code and the International Convention against doping in sport, the constraints and restrictions, but due to doping "zero-tolerance" attitude are generally not accepted, actually States, project associations, sports organizations of the doping provisions are inconsistent, contradictory or even slap in the face.

Whether certain substances should be included among banned substances list lacks scientific validation. For now, many are included in the prohibited list of substances (such as marijuana, THG, GH) function has not been clearly: does harm to the health of athletes using them? Whether it will help enhance an athlete's performance? And that's exactly what WADA important arguments against doping. Opinions on these substances, does not have a clear answer at the case, WADA will be included in the list of banned substances would have been too harsh, since the doping and have no adverse effects on the community, athletes as human rights were infringed.

To declare the whereabouts rules and biometric passports, two doping tests, regulation has been widely questioned. Whether it has accuracy: blood collection to of elevation height, and training situation, factors will effect the blood data, addition genetic gene exception also may produce fake positive results; suspected violations athletes privacy and liberty: because athletes not only must declared its whereabouts information, and its physiological Archives also was completely established; addition, since bio Passport cannot pointed out the name of doping drug used by athletes, and traditional doping check positive judge compared to, fined according to is "enough has persuasive".

It takes enormous works to implement most of the relevant anti-doping works. WADA's budget is half from the IOC and half from national Government. National anti-doping agencies receive very limited subsidies from the national sport federations and the Government. Face new development well ahead of detection methods for doping, doping tests whether it is technically, and financially are unable to cope.

The purpose of anti-doping is elusive. Researchers look forward to the doping control ideal for black and white: prohibited substance exists or does not exist in the sample or whether an athlete has used performance-enhancing drugs, yet most detection technology of material uncertainties and limitations to this ideal state of extreme uncertainty. World annually are too according to world anti-doping regulations developed of looks simple, and specific, and full, and has can operation sex of standard, on about 25 million cases sample for detection, but only has very minority of doping detection sample is positive, addition also has many number of athletes due to supervision and detection technology of limitations fluke escape has doping detection is positive of results. Meanwhile, WADA worried that athletes who use drugs will adapt to current detection techniques, but rarely announce the anti-doping laboratory processes, methods, and equipment, which in turn raises questions about fairness of anti-doping tests: the lack of transparency will result in lower quality of anti-doping work. In addition, the list of prohibited substances and methods is long, testing instruments and equipment so scarce (each substance or method requires at least one apparatus or equipment), there existed a "cat and mouse" and "the villains can always outsmart" the fundamental nature of that one "clean" sample never completely ruled out the use of performance-enhancing drugs.

What will be the Results if the Current "Zero-tolerance" Attitude Continued? Under the anti-doping purposes in rooting out doping, war on doping would become a global daily work. Meanwhile, in the short term, in UNESCO's InternationalConvention against doping in sport, supported by WADA and the IOC under the pressure, there will be an increasing number of countries, especially those countries that desire to host the Olympics, and will carry out specific legislation against agents. However, with more and more 
severe and widespread penalties issued, there will be an increasing number of athletes must be tested according to the ever-lengthening list of banned substances. On this way, war will be very anti-doping "spectacular" and "ambitious."

\section{Harm Reduction Strategy May Be the Alternative Way to Handle Doping}

War on Drugs Has Begun to Adopt a Harm Reduction Policy. In United States, Obama advocated on drug personnel "treatment mainly, combat supplemented by" of strategy, put focus on control drug needs Shang; United States national anti-drug policy Office Director Kelikesiji think the focus on the work should be the drug treatment to curb drug needs, which reduced world Shang of drug crime and violence activities; United States Justice Department Minister holder directly announced: "reduce on drug crime of sentenced".

Global Commission pointed the drug policy should be based on the principles of human rights and public health, and practical policy and local socio-economic and cultural characteristics of the premise of integration and sustainable development should be considered, then regulate the use of alternative medicines. The main measures include: needle and syringe exchange programs, construction of safety facilities and equipped with corresponding equipment purposes, sedative drugs instead of therapy, and the use of some drugs associated sampling and data analysis.

In the Netherlands " Coffee shop " where drug addicts can cannabis menu and eat a wide variety of cannabis, detailing their price and dosage on the menu, and then with his own syringe, such as taking, which greatly reduced the hepatitis and HIV The transmission rate of the virus, drug-related morbidity, mortality and crime rates significantly lower, reducing the financial burden of drug users, as well as government investment in social places of drug costs.

Dope war maybe use basic principles of harm reduction strategies. First, using a variety of methods or materials, including the use of pharmacological ways to improve their performance should be viewed as one of the sport's ultimate goal, and not, as is currently the case to go against the spirit of sports as an excuse to deny it. Because the sport is not entirely carried out in a fair environment, which is itself a celebration that brings together the difference: ethnic, economic and cultural background, competition rules, program characteristics, nutritional condition, training conditions, (competitions, training), regional climate and altitude, equipment, research and so on, there are many different and even unfair. In addition, stimulant quipped: "find out that stimulants check out is high-tech! It also reflects the reality of doping behavior and helpless. Performance-enhancing purposes are the essence of sports. Athletes will look for ways to improve the performance, such as changing the training mode, change their diet. And role model for athletes in competitive sports is also under the anti-doping war, describes the player as an ideal "perfect" people, but compared to other members of society the purpose of forcing athletes toward the direction of role models is not fair.

Second, athletes in sports health shall remain protected, but should take into account the specificity of risks in sports career. Researchers disable the stimulant is to protect athletes' health arguments tend to be idealistic, it ignored the sport itself harms to athletes and the harm itself is inevitable in sports: overload training day after day, special, early training, players are suffering from injuries, the pain, and even traumas of life. For risk assessment of the level of competitive sports can be carried out through some form of testing, while today's doping tests did not include it. Athletes will find ways to cheat in order to escape detection. But within the acceptable range, taking certain "doping" should be considered a part of the game.

Third, the list of banned substances should be shortened, should only list the ones that have been shown to improve performance and would cause harm to the body of the material. For example, remove marijuana from the disabled list, athletes as same as the general public should be permitted for therapeutic use, recreational or other purposes. Because neither test can prove that the use of cannabis and its derivatives can improve the results, nor can experiment prove that it can also hinder the improvement of scores. 
Fourth, researchers should strengthen inspection, but not suppress. The fact turns out, in Denmark, in gyms and health clubs, for the fitness using steroid, by introducing compulsory testing rather than suppressing, researchers can get better result. It was also demonstrated in the United Kingdom. In the United Kingdom, in order to lower the threshold for health care, steroid clinics offer free and anonymous service, such as free unused syringes, has attracted many steroid users to inject there. The data indicates that the current number of syringes injected steroid users has far exceeded the number of exchange of syringes for injecting drug users. In addition, the clinic doctor may contact with potential users directly, notifying them the dangers of doping and assisting their judgments and taking appropriate measures, such as whether it needs, continue to use or not? If you continue to use, what manner do you choose? Of course, these services need to be improved and corresponding evaluation criteria to be established.

Fifth, researchers need to strengthening education. Anti-doping education is the fundamental way to prevent the use of performance-enhancing drugs. Researchers should persist in prevention and education principles and constantly increase the intensity of anti-doping education in anti-doping war. The basic content of education includes general studies education, moral education, health education and legal education. Through opening anti-doping courses and lecture in related colleges, exhibition, hosting various type of anti-doping conference, establishing anti-doping website, publishing posters and knowledge manual, and anti-doping video products and books that is friendly to different communities, improve athletes, and coaches and the other athletes auxiliary personnel of anti-doping consciousness, enhance capacity of consciously boycott to doping, So as to continuously increase the athlete's anti-doping awareness of self-discipline.

Finally, it is proposed that the substituting methods for doping in sports should be investigated and evaluated by experimental research and adopting flexible alternative drug policies; it is also recommended that in the process of banning performance-enhancing drugs, researchers should respect human rights of athletes, pay attention to public health and regard athletes as a person not a criminal.

\section{Summary}

The strategy and direction of the anti-doping war need to be further argued and reformed.

\section{Acknowledgement}

This work was supported by Administration of Sports in Jiangsu under the grant ST1330029.

\section{References}

[1] Information on http://news.xinhuanet.com/world/200906/26/content_11606460.htm.

[2] Information on http://world.people.com.cn/GB/157278/17258046.html.

[3] Information on http://www.legaldaily.com.cn.

[4] Information on http://news.sohu.com/20130401/n371237456.shtml.

[5] Information on http://news.xinhuanet.com/world/2014-01/03/c_125950302.htm,.

[6] Information on http://news.sohu.com/20131211/n391613520.shtml.

[7] Information on http://sports.ifeng.com.

[8] D Angelo C and Tamburrini C, “Addict to win? A different approach to doping," Med Ethics, vol. 36, pp.700-707, 2010. 
[9] Mc Veigh J, Beynon C, Bellis Ma, 'New challenges for agency based syringe exchange schemes: analysis of 11 years of data (1991-2001) in Merseyside and Cheshire, United Kingdom", International Journal of Drug policy, vol. 14, pp. 399-405, 2003.

[10] Jones L, Pickering L, Sumnall H, McVeigh J, Bellis MA., "Optimal provision of needle and syringe programs for injecting drug users: A systematic review,” International Journal of Drug policy, vol. 21, pp. 335-342, 2010.

[11] Bengt Kayser, Alexandre Mauron and Andy Miah, Current anti-doping policy: a critical appraisal, BMC Medical Ethics, 2007, 8.1:2.

[12] Kayser, Bengt, and Barbara Broers. "The Olympics and harm reduction." Harm reduction journal, 2012, 9.1:33-7517.

[13] Kirkwood, Ken. Considering harm reduction as the future of doping control policy in international sport, Quest, 2009, 61.2: 180-190. 